\title{
MEDIASTENIN AKUT VE KRONIK ENFEKSIYONLARI
}

\author{
Dalokay KILIÇ \\ Başkent Üniversitesi Tıp Fakültesi, Göğüs Kalp ve Damar Cerrahisi Anabilim Dalı, Ankara, Türkiye \\ e-posta: dalokay7@yahoo.com \\ doi:10.5152/tcb.2011.13
}

Mediastinit oldukça ölümcül seyredebilen, göğüs ve kalp cerrahisi doktorlarının dikkatle üzerine eğildiği bir hastalıktır. Mediasten dokusunun iltihabıdır. Akut ve kronik şekilde enfeksiyon ve enfeksiyon dışı etyolojiler ile karşımıza çıkabilir. Akut mediastinitlerin çoğu özefagus perforasyonuna veya göğüs travmasına sekonder olarak gelişebilir. Kronik form veya yavaş gelişen form ise tuberküloz, histoplasmozıs gibi bakteriel veya fungal enfeksiyonlara veya sarkoidoza ikincil gelişen durumdur.

Bu bölümde mediastinitlerin tanı ve tedavi metodları literatür eşliğinde gözden geçirilmiştir.

\section{Akut Mediastinit}

Akut mediastinit tüm tıbbi gelişmelere rağmen günümüzde halen ciddi bir klinik antite olarak kalmıştır. Mediastenin gözeli bir doku olması, kalbin ve akciğerin hareketi ile mikroorganizmaların daha hızlı yayılabilme olasılığı, ayrıca en sık etken özefagus rüptürü olduğu için özefageal içeriğin (ph=1.5) reflü ile ve tükürük içeriğinin mediastene yayılabilmesi (kimyasal mediastinit) özefageal mukozanın mikroorganizma içeriği nedeni ile enfeksiyonun çok çabuk yayılma ve şiddetlenme eğilimi mevcuttur. Mutlak hızı tedavi protokolü geçerlidir.

\section{Etken}

Akut mediastinitin primer etkenler içinde en sık nedeni özefagus perforasyonudur (\%90). Özefagus perforasyonunuda da ise en sık etken iatrojenik (endoskopik dilatasyon sırasında, operasyon sırasında), yabancı cisim aspirasyonu ile özefagus laserasyonu, eksternal travmalar (delici kesici alet yaralanmaları), Boerhaave sendromu, kusmalar, koroziv yanıklar, kan- ser, divertikul gibi diğer nedenler sayılabilir. Ayrıca diğer primer nedenler trakeo-bronşial yaralanmalar ve mediasten kardiak ameliyatlara ikincil gelişen enfeksiyonlardır. Sekonder nedenler ise akciğer ve plevra enfeksiyonlarının mediastene ulaşması ve lenfohematojen yayılımdır (Tablo 1). Özefagus rüptürü ayrıca abdominal basıncın ani arttığı gastrik sıvının özefagusa şiddetli (hızlı ve basınçlı) geçişi sonucu (abdominal travmalar) oluşan rüptürdür. Genellikle sol tarafda diyafragmanın bir kaç $\mathrm{cm}$ üzerinde periözefageal destek dokunun en zayıf olduğu seviyede oluşur. Bu mekanizma kusma sırasında oluşur ise Boerhaave sendromu olarak adlandırıır. 4 ve 6 saat içinde mediastinal plevra açılarak akut nekrotizan mediastinite dönüşebilir. Ayrıca retrofarengeal apsenin (dental enfeksiyon) mediastene inmesi ile mediastinit gelişebilir $(1,2)$. Özellikle retrofarengeal apseye eşlik eden medikal tedaviye dirençli ateş saptandığına mutlak mediastinal apse akılda buludurularak toraks bilgisayarlı tomografi (toraks BT) ile tetkik edilmelidir. KIlıç ve ark. bir çalışmalarında iki dental apse, bir yabancı cisim travması ile oluşan üç retrofarengial apse sonrasında desenden mediastinit geliştiği üç vakadan bahsetmişlerdir. Üç vakaya da agresif cerrahi yaklaşlarak torakotomi yapılmış ve bir hasta ek olarak servikal drenaj ile tedavi edilmiştir (1). Burada mekanizma retrofarengeal bölgeden parafarengeal yol boyunca posterior mediastene enfeksiyonun ilerlemesidir. Retrofarengeal boşluk bukkofarengeal fasia ve prevertebral alan arasındadır. Ayrıca anterior bölge ikinci torasik vertebra, posterior kompartman ise özofagus ve prevertebral bölge arasında diyafragmaya kadar ilerler $(3,4)$.

Koroner arter cerrahisi sonrasında da ne yazık ki, belli oranda mediastinit halen görülmektedir. Risnes ve ark. koroner arter by-pass greft uygulanmış 18.532 
Tablo 1. Tabloda akut ve kronik mediastinitin başlıca nedenleri özetlenmektedir.

\begin{tabular}{|l|l|}
\hline Akut Mediastinit nedenleri & \\
\hline Özefagus Perforasyonu & Sternotomi sonrası \\
-latrojenik & -Açık kalp ameliyatları \\
-Travma (delici kesici) & - Göğüs cerrahisi vakaları \\
-Abdominal travma (basınç ile) & Retrofarengeal apse \\
-Boerhaave & -Dental enfeksiyonlar sonrası \\
-Koroziv yanıklar & \\
-Kanser & \\
-Divertikulit & \\
\hline Kronik Mediastinit nedenleri & \\
\hline Enfeksiyonlar & Otoimmun hastalıklar \\
-Tuberküloz & -Behçet Hastalığı \\
-Histoplazmosiz kapsulatum & Radioterapi \\
-Blastomikosiz & Ilaç \\
-Amip apsesi & -Metisergide maleat \\
-Hidatik kist & \\
\hline
\end{tabular}

hastanın 107'sinde (\%0.6) mediastinit saptamışlar, bağımsız risk faktörlerini ise, ileri yaş, erkek cinsiyet, sol inen koroner arter stenozu, obesite, kronik obstruktif akciğer hastalığı, diabet, ve kan transfüzyonu olarak saptamışlardır (5).

\section{TANI}

Akut mediastinitde klinikte genel durum bozukluğu, ateş yüksekliği, yüksek nabız mevcuttur. Özefagus perforasyonunda özellikle boyunda trakeobronşial yaralanmada olduğu kadar gergin olmayan bir cilt altı amfizemi mevcuttur. Direk akciğer grafisinde mediasten genişlemiştir (erişkin hastada yatar durumda $6 \mathrm{~cm}$ oturur durumda $4 \mathrm{~cm}$ ). Baryumlu özefagografi veya opak madde içerilerek çekilen toraks BT de opak maddenin mediastene geçiyor olması önemli teşhis metodudur (6) (Resim 2). Ayrıca endoskopi de uygulanabilecek bir tetkikdir. Toraks tomografisi bulguları olarak mediastinal yağ doku attenuasyonunda artma (\%100), lokalize mediastinal sıvı kolleksiyonları (\%55) (Resim 1, 2), mediastende serbest gaz odacıkları (\%57.5), mediastinal lenf nodları (\%35), perikardial (\%27.5), ve plevral efüzyonlar (\%85), akciğer parankim infiltrasyonları (\%35), sternal ayrılma (\%40), ve pleuromediastinal fistül (\%2.5) çeşitli oranlarda görülebilmektedir (7). Toraks BT sensitivite ve spesifitesi postoperatif dönemde ilk 17 günde sırası ile $\% 100$ ve $\% 3317$. günden sonra ise $\% 100$ and $\% 90$ olarak sap- tanmıştır $(7,8)$. Yamashiro ve ark. kalp ameliyatı için yapılan sternotomi sonrası mediastinitlerde toraks BT spesifitesinin ikinci 21 . günde $\% 30$ dan $\% 85$ oranına yükseldiğini belirtmişlerdir (9).

\section{TEDAVi}

Özefagus perforasyonu saptandığında acil olarak torakotomi ile girişim uygulanarak özefageal tamir yapılmalıdır. İlk 24-48 saat içinde bu geçerlidir. Kırksekiz saati geçtiğinde ise hastayı septik tablodan korumak için drenaj (torakoskopik veya açık cerrahi) ve gastrostomi ile gastroözefageal reflünün dekomprese edilmesi, ayrıca özefagus üst uç servikal bölgeye açarak (özefageal diversiyon) tükürük salgısının ve oral floranın mediasteni kontamine etmesine engel olunabilir. Özefagus perforasyonunda reflü ve tükrük salgısı ile kimyasal mediastinit tehlikesi olduğundan yaklaşım için acele edilmelidir. Hastanın yaşı, genel kondüsyonu, immun yetmezlik yapabilecek bir hastalık veya diyabet gibi enfeksiyona yatkınlık oluşturabilecek hastalıklarının bulunması mediastinit progresyonunu kolaylaştırabilir, ancak tanının çabuk konulması, yeterli drenaj, agresif cerrahi yaklaşım, hastanın nütrisyonel desteği, yoğun bakım desteği, ve uygun ve yeterli antibiyotik desteği tedavinin etkinliğini belirleyen faktörlerdir (10). Girişim erken dönemde videotorakoskpik olarak yapılarak da drenaj sağlanabilir (11). 

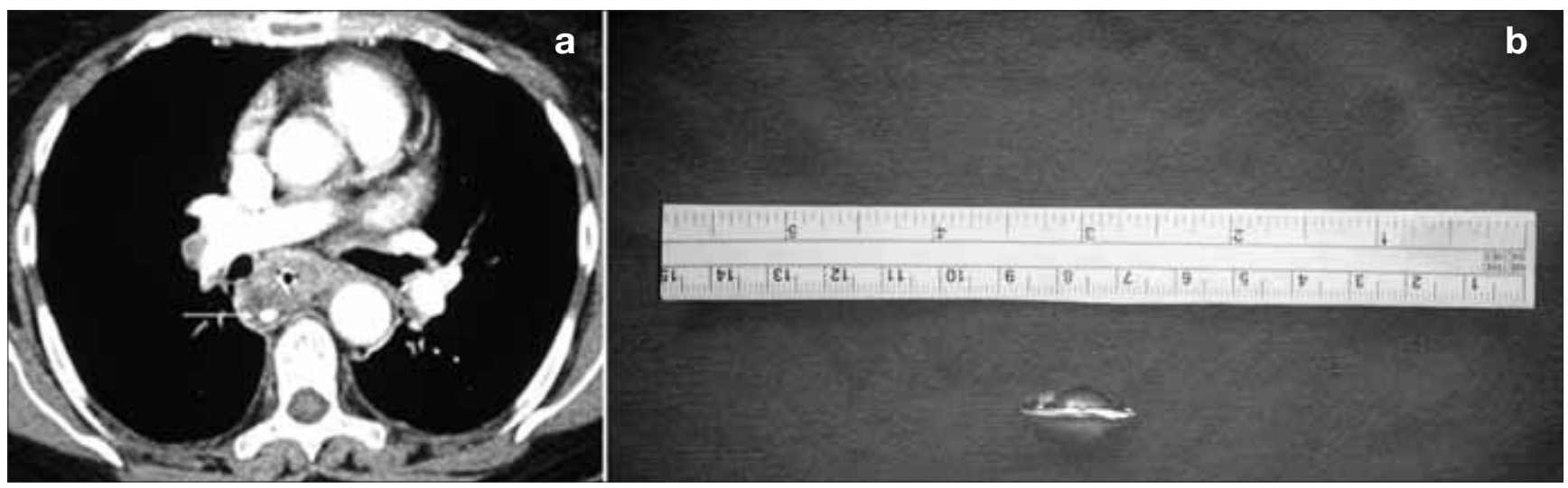

Resim 1. Ellidört yaşında kadın hasta yabancı cisim perforasyonu sonucu retrofarengeal apse ve mediastinal apse nedeni ile çekilen toraks BT görüntüsünde paraözefageal sıvı içinde yabancı cisim görünümü (a), sağ torakotomi ve mediastinal plevra açılarak drenaj ve yabancı cismin çıkarıldıktan sonra görünümü (b)
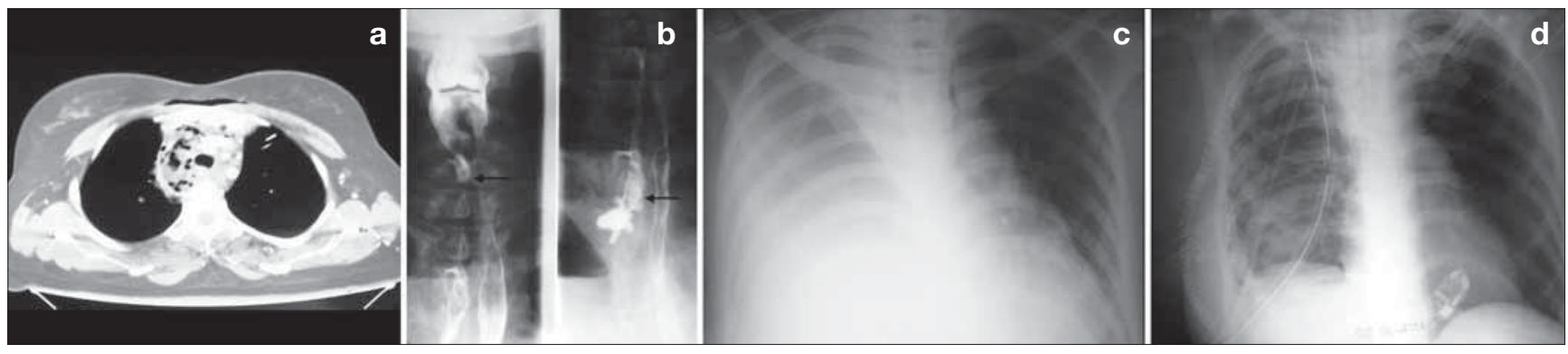

Resim 2. Otuziki yaşında bayan hasta bir dış merkezdeki entubasyon sırasında özefagus perforasyonu sonrasında oluşan mediastinal apse sağ hemitoraksa açılmış, hasta ampiyem, mediastinit tablosu ile kliniğimize başvurduğunda sağ posterolateral torakotomi, drenaj ayrıca mediastinal plevra açılarak kronik drenaja alındı. Ayrıca jejunostomi ve özefagus üst uç diversiyon uygulandı. Resimlerde dış merkezde çekilmiş toraks BT'de, hava-sıvı seviyeleri ile mediastinal apse görünümü (a), özofagus pasaj grafisinde opak maddenin mediasten ve sağ hemitoraks geçişi görülmektedir (siyah ok) (b) Ayrıca PA akciğer grafisinde ise plevral mayi (c) ve postoperatif görünümü (d) izlenmektedir.

\section{Kronik Mediastinit}

Mediastenin başlıca tuberküloz ve fungal enfeksiyon nedeni ile fibrozise uğramasıdır. Mediasten fibrozisi ender görülen aselüler kollajen ve fibroz doku birikiminin neden olduğu benign bir hastalıktır. Flieder ve arkadaşları mediasten fibrozisi yerine mediastenin idiopatik fibro-inflamatuar lezyon şeklinde bir isimlendirmeyi öne sürmüşlerdir (12).

\section{ETKEN}

En sık nedeni tüberküloz ve fungal enfeksiyonların neden olduğu granülomatöz hastalıklardır. Amerika Birleşik Devletleri'nde anormal immün yanıt nedeni ile etken daha çok histolazma kapsulatum olarak belirtilmiştir (13). Ayrıca sifiliz, blastomikozis ve amip apseleri, kist hidatik gibi paraziter hastalıklar nedeni ile de oluşabilir. Mediasten fibrozisi etyolojisi için nedeni bilinmeyen bir grup hasta da mevcuttur (Tablo 1). Hasta yaş grubu genellikle gençtir.

\section{TANI}

Etkilenen hastalar genellikle vena kava superior, pulmoner ven veya arterler santral hava yollarının ve özefagus obstruksiyon semptomları ile kliniğe başvururlar. Matisen ve ark. Histoplazma kapsulatum nedeni ile tedavi ettikleri 20 hastada nefes darlığı (hasta sayı$\mathrm{s}=8, \% 40$ ) hemoptizi (hasta sayısı=6, \%30), obstuktif pnomoni (hasta sayısı=5, \%25) superior vena kava sendromu (hasta sayıSı=2, \%10) saptamışlardır (14). Toraks BT ve MR görüntüleme yöntemleri tanı için başlıca seçeneklerdir. Toraks BT bulgularında başlıca, lokalize ve diffüz tutulum görülür, ayrıca kalsifikasyon buna eşlik edebilir (Resim 1, 2). Daha çok anterior mediastinal kompartmanda tutulum saptanır. Özellikle superior vena kava ve pulmoner arter etrafında tutulum görülür. Mediasten fibrozisinde fokal ve diffüz olmak üzere iki tip radyolojik görüntülenme tarif edilmiştir. Fokal tip genellikle toraks BT ve toraks MR ile paratrakeal, subkarinal veya pulmoner hilusta kalsifikasyonlar içereren lezyonlar şeklinde görülmektedir. Diffüz form 
ise genellikle kalsifiye olmayan bir çok mediastinal kompartmanda diffüz infiltratif tutulum şeklinde kendini gösterir (15). Transtorasik tru-cut biyopsi veya mediastinoskop ile alınan doku biopsisi ile kesin tanı koymak mümkündür. Mikroskopik olarak hyalinize konnektif fibröz doku aralarında plazma hücre ve lenfosit agregatları bulunur. Fibroblastlar bu proliferatif aktiviteyi indüklemektedir. Ayrıca buna venulit eşlik edebilir. Özellikle Hodgkin ve yüksek gradeli B hücreli sklereozan lenfoma ayırt edilmelidir. Yeterli miktarda alınan doku ile yapılan biyopsi ve immünokimyasal çalışma ile ayırıcı tanı kolaylıkla yapılabilmektedir (16).

\section{TEDAVi}

Mediastinal fibrozis sıklıkla anlaşılamayan biçimde spontan iyileşme veya semptomlarda alevlenme şeklinde kitle volum artışı ile seyredebilir. Loyd ve arkadaşları bu hastalıkda mortalite oranını \%30 şeklinde belirtmişlerdir. Ölüm nedenleri sıklıkla tekrarlayan enfeksiyonlar, hemoptizi kor pulmonale eşlik eden sağ kalp yetmezliği nedeni ile olmaktadır. Mortalite oranı diffüz formda daha yüksek olarak saptanmıştır (17).

Sistemik antifungal tedavi, cerrahi eksizyon ve komplikasyonların lokal tedavisi gibi başlıca üç tedavi şeklinden söz edilebilir. Diffüz formda Histoplazma kapsulatum'un ketakonazol ile tedavisi veya ikincil gelişen fibrotik reaksiyonuna yönelik ise steroid tedavisi uygulanmaktadır (18). Lokal formuna ve daha çok histoplasma etyolojisi dışındaki vakalarda ise cerrahi ekzisyon ile semptomlarda belirgin düzelme saptandığına ilişkin yayınlar mevcuttur $(19,20)$. Tamoksifen ve steroid tedavisinin oldukça etkili olduğunu belirten yazarlar mevcuttur (19). Komplet rezeksiyon için damar ve hava yolları için rekonstruksiyon gerekli olabilir ama bu teknik yüksek mortalite ve komplikasyon oranı ile yönelik çok fazla tercih edilmemektedir $(17,21)$. Matisen ve arkadaşları 20 vakalık serilerinde 18 hastaya rezeksiyon uygulamışlar, 4 (\%20) hasta postoperatif dönemde kaybedilmiştir (14). Vena kava superior ve pulmoner artere stent konularak obstruksiyon açılmış vakalar mevcuttur (22-24).

Sonuç olarak akut mediastinit etkene yönelik özellikle özofagus perforasyonunda hızlı ve yeterli drenaj, uygun antibiyoterapi ve yoğun bakım koşulları ile düşük mortalite ve morbidite oranı ile, kronik mediastinit ise etken saptandıktan sonra palyatif ve kesin yöntemler ile tedavi edilebilir hastalıklardır.

\section{KAYNAKLAR}

1. Kilic D, Findikcioglu A, Ates U, Hekimoglu K, Hatipoglu A. Management of Descending Mediastinal Infections with an Unusual Cause; A report of 3 cases. Ann Thorac Cardiovasc Surg 2010;16:198-202.

2. Makeieff M, Gresillon N, Berthet JP, et al. Management of descending necrotizing mediastinitis. Laryngoscope. 2004;114:772-5.

3. Hollingshead WF. The fascia and spaces below the hyoid bone. In: Anatomy for Surgeons. New York: Harper \& Row; 1982;271-8.

4. Ojiri H, Tada S, Ujita M, et al. Infrahyoid spread of deep neck abscess: anatomical consideration. Eur Radiol. 1998;8:955-9.

5. Risnes I, Abdelnoor M, Almdahl SM, Svennevig JL. Mediastinitis after coronary artery bypass grafting risk factors and long-term survival. Ann Thorac Surg. 2010;89:1502-9.

6. De Lutio di Castelguidone E, Pinto A, Merola S, Stavolo C, Romano L. Role of Spiral and Multislice Computed Tomography in the evaluation of traumatic and spontaneous oesophageal perforation. Our experience. Radiol Med. 2005;109:252-9.

7. Exarhos DN, Malagari K, Tsatalou EG, et al. Acute mediastinitis: spectrum of computed tomography findings. Eur Radiol. 2005;15:1569-74.

8. Akman C, Kantarci F, Cetinkaya S. Imaging in mediastinitis: a systematic review based on aetiology. Clin Radiol. 2004;59:573-85.

9. Yamashiro $\mathrm{T}$, Kamiya $\mathrm{H}$, Murayama $\mathrm{S}$, et al. Infectious mediastinitis after cardiovascular surgery: role of computed tomography. Radiat Med. 2008;26:343-7.

10. Ragusa M, Avenia N, Fedeli C, et al. Acute mediastinitis: clinical features and review of a case load. Chir Ital. 2003;55:519-24.

11. Cho JS, Kim YD, I H, Lee SK, Jeong YJ. Treatment of mediastinitis using video-assisted thoracoscopic surgery. Eur J Cardiothorac Surg. 2008;34:520-4.

12. Flieder DB, Suster S, Moran CA. Idiopathic fibroinflammatory (fibrosing/sclerosing) lesions of the mediastinum: a study of 30 cases with emphasis on morphologic heterogeneity. Mod Pathol 1999;12:257-64.

13. Fijołek J, Wiatr E, Błasińska-Przerwa K, Roszkowski-Sliz K. Fibrosing mediastinitis as an untypical complication of tuberculosis: case report. Pol Arch Med Wewn. 2009;119:752-5.

14. Mathisen D.J, Grillo H.C. Clinical manifestation of mediastinal fibrosis and histoplasmosis, Ann Thorac Surg 1992;54:1053-8.

15. Rossi SE, McAdams HP, Rosado-de-Christenson ML, Franks TJ, Galvin JR. Radiographics. Fibrosing mediastinitis.2001;21:737-7.

16. W.A Fry, T.W Shields. Acute and chronic mediastinal infections. In: T.W Shields, Editor, Mediastinal surgery, Lea \& Febiger, Philadelphia 1991;101-8.

17. Loyd JE, Tillman BF, Atkinson JB, Des Prez RM. Mediastinal fibrosis complicating histoplasmosis. Medicine (Baltimore) 1988;67:295-310.

18. Urschel HC, Jr, Razzuk MA, Netto GJ, Disiere J, Chung SY. Sclerosing mediastinitis: improved management with histoplasmosis titer and ketoconazole. Ann Thorac Surg 1990;50:215-21. 
19. Savelli B.A, Parshley M, Morganroth M.L. Successful treatment of sclerosing cervicitis and fibrosing mediastinitis with tamoxifen, Chest 1997;111:1137-40.

20. Dunn EJ, Ulicny KS, Jr, Wright CB, Gottesman L. Surgical implications of sclerosing mediastinitis: a report of six cases and review of the literature. Chest 1990;97:338-46.

21. Levashov Yu N, Yablonsky PK, Cherny SM, Orlov SV, Shafirovsky BB, Kuznetzov IM. One-stage allotransplantation of thoracic segment of the trachea in a patient with idiopathic fibrosing mediastinitis and marked tracheal stenosis. Eur J Cardiothorac Surg 1993;7:383-6.
22. Ferguson ME, Cabalka AK, Cetta F, Hagler DJ. Results of intravascular stent placement for fibrosing mediastinitis. Congenit Heart Dis. 2010;5:124-33.

23. Guerrero A, Hoffer EK, Hudson L, Schuler P, Karmy-Jones R.Treatment of pulmonary artery compression due to fibrous mediastinitis with endovascular stent placement. Chest. 2001; 119: 966-8.

24. Thiessen R, Matzinger FR, Seely J, Aina R, Macleod P. Fibrosing mediastinitis: successful stenting of the pulmonary artery. Can Respir J. 2008;15:41-4. 